\title{
Singapore Medical Journal in the age of social media
}

\author{
Chew Lip $\mathrm{Ng}^{1}$, MBBS, FAMS, Kian Keong $\underline{P o h^{1}}$, MBBChir, FACC
}

$\mathrm{S}$ ocial media is now a ubiquitous channel for information dissemination, including the dissemination of scientific knowledge. Journals are increasingly tapping on social media platforms as novel channels for dissemination, unbridling the works of scholarship previously bound within their covers. ${ }^{(1)}$ From antiquity till before the information revolution, knowledge was transmitted via one of two means - verbal communication and written or printed material. From the 1990s, a new channel of knowledge distribution was created - the Internet, which rapidly transformed knowledge dissemination.

It is not hyperbole to suggest that most of us have been accessing scientific articles in soft copy via the Internet for the past decade or so. Fast forward to today, and the Internet has penetrated further into our lives through social media, affording journals new channels to reach out to readers in ways previously never thought possible.

When we examine the fundamental functions of scientific journals, they are to provide a platform for researchers to share their research findings with others and for readers to obtain the most current knowledge. ${ }^{(2)}$ On our journal's website, it is written: "The Journal aims to advance medical practice and clinical research by publishing high-quality articles that add to the clinical knowledge of physicians in Singapore and worldwide".

While the Internet brings challenges, as detailed in a previous editorial, it also brings opportunities. ${ }^{(3)}$ The Editorial Board believes that it is important for the Singapore Medical Journal to move with the times. ${ }^{(4)}$ In line with advancing the journal's mission, we have drawn up several social media strategies to disseminate research works published in our journal, engage readers more actively and add value to authors who have chosen to publish with us. We began with our readers in mind, and then built the profiles of our readers (Box 1) to determine how we can best reach and engage you.

Based on the above reader profiles and the journal's functions, we have crafted our social media strategies (Fig. 1). To execute this strategy, we have developed a presence on these platforms: Twitter, Facebook and Linkedln. The types of posts will include: (a) posts that summarise new articles and provide links to the full articles; (b) journal announcements on events, new issues and calls for paper; (c) infographics and

\section{Box 1. Profile of Singapore Medical Journal readers:}

\section{Researchers and scientists}

- Key sources of research works

- Interested in keeping tabs on the latest research findings in their fields

- Keen to promote their research to a wider audience, enhancing visibility of their works and profile(5)

- Keen to discuss their ideas and research in-depth verbally

- Keen to engage key opinion leaders in discussion and consultation

- Interested in becoming thought leaders and influence their own research communities

- May be more inclined to submit articles to a journal that can offer them a platform that fulfils the above ${ }^{(5)}$

2. Family physicians and specialists in public or private practice

- Busy clinicians who may not read through an entire article

- Interested in new knowledge relevant to their practice to keep up to date

- Listening to short podcasts/audio clips on relevant topics may be an appealing and efficient way to obtain knowledge and information

- Summaries of articles and infographics may appeal to these readers

3. Medical students and residents

- Busy with training and examinations

- Tech-savvy and likely active on social media

- Likely to access interesting research findings visible on social media

- Social media is one way to engage this younger group and get them interested in reading research articles and engage in research activity

- Can be a key source of dissemination of impactful research and knowledge via social media networks

visual representations of new articles; (d) podcasts and videos on interviews with authors and opinion leaders on new articles, and narrated summaries of articles; (e) related content from other journals and knowledge sources; and (f) short profiles of authors.

We are excited by the prospects of enhancing the reach and functions of the journal, and look forward to interacting with you on Twitter, Facebook and Linkedln. We hope you will support the journal by following us on these social media platforms, and sharing, forwarding and discussing published articles on the platforms. 


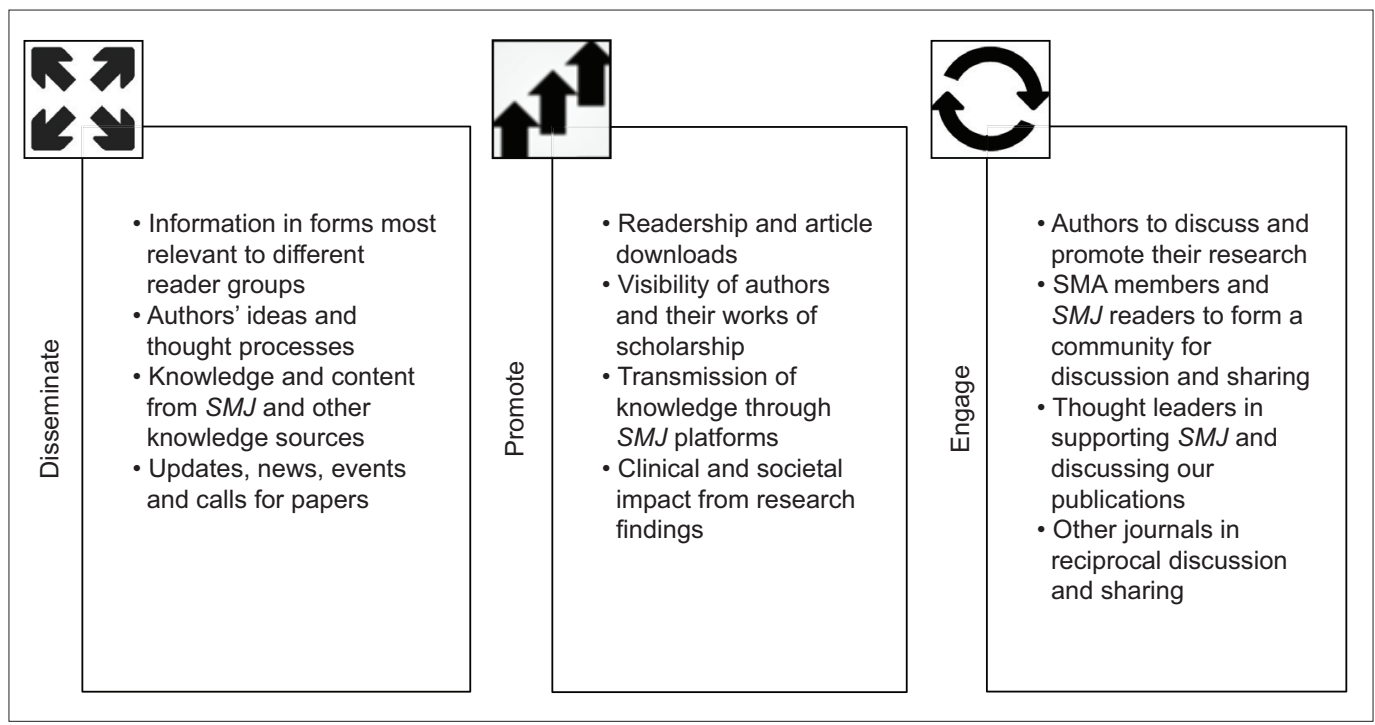

Fig. 1 Diagram shows the social media strategy for the Singapore Medical Journal (SMJ). SMA: Singapore Medical Association

\section{REFERENCES}

1. Trueger NS. Medical journals in the age of ubiquitous social media. J Am Coll Radiol 2018; 15(1 Pt B):173-6.

2. Poh KK. Increase in impact factor for the SMJ. Singapore Med J 2018; 59:345.
3. Poh KK. Journal publishing in our connected world. Singapore Med J 2019; 60:1-2.

4. Poh KK. A time for reflection for thanks. Singapore Med J 2018; 59:1.

5. Poh KK. Moving forward in the new year. Singapore Med J 2017; 58:1. 